\title{
Analytic solutions of college scientific achievement assessment
}

\author{
Guixue HU
}

\author{
Animal Science and Technology College, Jilin Agricultural University, Changchun, 130118, China \\ email: huguixue901103@163.com
}

Keywords: College; Scientific research achievement; Reform of evaluation system

\begin{abstract}
Evaluation of scientific research achievement is an important and basic work of science and technology management in university. College teachers are the main forces undertaking scientific activities. To improve their initiative and scientific research quality, a scientific and reasonable system which can assess college teachers' scientific research achievements needs to be established .Currently, there are still some problems exist in evaluation of college scientific research in our country including imperfections of evaluation system, unreasonable evaluation set and poor implementation process, which need to set up data management systems, enhance and perfect the system,etc.,to make the evaluation process more scientific, normative, reasonable and available.
\end{abstract}

\section{Introduction}

Evaluation of scientific research, in essence,is an activity of cognition to determine the output and effect of scientific activities. Evaluation of scientific research achievement is an essential part of scientific assessment and it also plays a key role in college scientific decision-making and optimal allocation of resources, promting science management and research achievement of research teams and basic organizations and motivating technical innovation and passion of researchers.

\section{Features of college scientific research assessment}

Coexistence of scientific research and teaching. The university is shouldering the dual task of teaching and research which integrates promotes and interacts with each other. More and more college teachers have to undertake teaching and scientific work. With the increasing integration, the budget devotion and output is hard to separate. Therefore, in establishing the evaluation system, how to balance the relationship between teaching and scientific research achievement, and how to solve the problem of achievement statistics due to integration is what the college scientific research assessment system has to face and deal with.

Coexistence of various scientific activities. With the increase of national science and technology input, The colleges participate in research shows an increasing width and depth. The types of scientific research projects ranging from basic research and applied basic research project to applied research projects and the industrialization of technological achievements which can solve the national science and technology development and meet the needs of national economic and security construction. Moreover, many research universities have both liberal arts and science, containing natural science and social science research. Therefore, the differences among basic research and applied research, natural science and social science need to be take into account ${ }^{[1]}$.

Coexistence of various scientific achievements.College scientific achievements have various forms, including papers, books, awarded achievements, patents, personnel cultivation, economic profits and social impacts. Besides,each achievement has several grades. For example, awarded achievements consist of national and provincial science and technology achievement award. Various forms, hysteresis and the complexity of scientific and achievements have made scientific assessment more complex.

Coexistence of various objects in scientific achievements evaluation.Evaluation of scientific research achievements not only refers to scientific researchers and projects,but research teams and 
basic organizations. Characteristics of different evaluation objects need to be considered, which the evaluation system should be targeted to, instead of one size fits all. Recently, our country advocates construction and development of science and technology innovation teams, which is the same with college. How to scientifically and objectively evaluate the performance of science and technology innovation team scientific research needs to be further researched urgently ${ }^{[2]}$.

\section{Current state of college scientific research assessment}

College scientific research assessment indicators.Establishment of scientific evaluation system is the basis and also the key to science and technology evaluation. At present, many colleges and universities combine their own characteristics to establish a scientific achievement evaluation system, especially for researchers evaluation. Scientific achievement evaluation system for University researchers, for example, despite the evaluation system established by the university vary, it generally include an indicator and research funding, scientific and technological achievements, academic activities and scientific and technological input-output ratio, as well as several secondary indicators. Some schools also set up principal and secondary indicators for scientific research process management and personnel cultivation.

In terms of specific indicators, the set of college funding and principal research projects indicators mainly based on different sources of the projects, which can be divided into two secondary indicators, longitudinal research projects and horizontal research projects. Longitudinal research projects, set by project grades, including major national projects, state-level key projects, national common project, provincial major projects, provincial general project, as well as basic research projects, applied basic research projects, certain types of applied research projects, engineering projects, international scientific and technological cooperation projects etc.,while horizontal research projects based on funds. Scientific achievements as an important research output indicators, including academic, scholarly works, identification results, intellectual property rights, the award-winning achievement, achievement transformation. For papers in the design process, more metrics for different levels of journals details should be considered to grant different ways possible to distinguish and reflect the different levels of academic value. Academic writings emphasize the importance of academic monographs, edited, textbooks and distinguish the difference between different levels of the same category of work, combined with consideration of the number of text books in the same level. Patents, awards and other achievements should also be considered separately in accordance with the trade-offs of different types or levels ${ }^{[3]}$.

In addition, as for the humanities and social sciences research, most schools are given special consideration; for more inter-university teachers and students, cooperations between teachers are also given special consideration.

Problems exist in college scientific research assessment. First, college evaluation system lacks overall planning and construction. Evaluation of science and technology achievement for researchers, to a certain extent,is the university internal self-build evaluation standard, and has been implemented in some institutions. The results of the evaluation has become part of the annual assessment of researchers and universities, allowance allocation , job classification and other key indicators and evidence. But, recently, with the establishment of scientific innovation teams, and research institutes, how to evaluate the achievement of research teams and institutions is a new task to be solved. With implementation already being explored, colleges still lack overall planning and thinking on university research achievement evaluation system. For colleges and universities, there are many different types of national research projects, different types and levels of the research teams, research institutions and platforms, only evaluation of personnel scientific achievement is not enough. Overall evaluation system planning and construction should be done ${ }^{[4]}$.

Second, the setup of scientific research performance evaluation index system is unreasonable, and its effective implementation rate is rather low. There are various forms of scientific and technological activities. Those of different types and in different fields are not same either. So are the output forms of science and technology which contain papers, patents, personnel training, and so on. 
Although the performance evaluation of scientific research activities have carried out in colleges and universities for many years, the number of real effective implementation is not much. For one reason, the human resources performance evaluation, subject evaluation, teaching evaluation and other school-related evaluation work still has certain difficulty in effectively combining to each other, because of the limitation of the management system in Colleges and universities and the lack of a strong promotion policy. For another reason, index system itself has poor operability. Scientific and technological evaluation of basic data is unsystematic and incomplete which is also a very important reason.

\section{Countermeasures for the development of performance evaluation system of scientific research in Universities}

In order to strengthen the construction of university scientific research performance evaluation system and create a good scientific research environment, colleges and universities not only need to make the performance evaluation of scientific research in colleges and universities institutionalized, scientific, and standardized, but also continue to establish and improve the system of scientific research performance evaluation. And combining their vital interests and long-term development close together. Establishing an incentive mechanism of scientific performance evaluation, and making full use of its results. It is more important to combine it with the allocation of scientific and technological resources, the introduction of talent, the support of funds, and so on. However, the establishment of the system, cannot restrain the innovation power of scientific research personnel. Provide a good environment and a motivation for scientific research personnel that encourage them to research instead of pressure ${ }^{[5]}$.

Improve the performance evaluation index system of scientific research, and enhance the implementation of evaluation.

Construction of performance evaluation index system of scientific research is a highly complex and difficult work in the process of Performance evaluation of scientific research. In the basis of summarizing the current university scientific research performance evaluation work, drawing lessons from the domestic and foreign advanced evaluation methods and experience. Based on national conditions and the specific circumstances of the school, and actively explore, constantly improve and perfect the performance evaluation of scientific research in colleges and universities in the establishment of the evaluation index. Consideration should be given to the balance between academic quality and quantity. Adhere to the quality oriented principle. On the basis of quality assurance, we should make clear that the maximum value of academic research is qualitative, rather than the quantity of output. In the period of paying attention to science and technology innovation, we should increase the evaluation of innovation ability and contribution of research specialist staff. On the construction of performance evaluation system of scientific research in colleges and universities, we should establish scientific research personnel, scientific research team, research institutions and other scientific research performance evaluation index system respectively. At the same time, pay attention to the mutual coordination of other evaluation systems, such as subject evaluation, teaching evaluation and other evaluation system. Only a multi-faceted, multi angle comprehensive consideration, and constant sum-up and improvement makes it possible to for performance evaluation system of scientific research in colleges and universities to be more scientific, fair and reasonable.

Establish public evaluation data management system, and promote the integration of evaluation work

Establish and perfect the public management information system which covers the basic data of academic papers, works, awards, patents, etc. Provide technical support for the implementation of the performance evaluation system of scientific research. In the long run, the establishment of the basic platform for the evaluation of the whole school will make the school subject evaluation, teaching evaluation, scientific research evaluation and other types of evaluation coordinated. On the basis of this, the repetition of all kinds of evaluation work will be reduced, the integration, efficiency and order of the school evaluation work will be promote. 


\section{References}

[1] Zhang Xun. Effects of university teacher's academic pressure on research performance[J]. Studies in Science of Science,2014(4):549-558.

[2] Zhu Yani.A research on the evaluation system of university scientific research performance based on collaborative innovation[J].Science Research Management,2016(4):180-187.

[3] Yang Liansheng, Qian Tiantian, Wu Zhuoping. Research on the influence factors and mechanism of the cross disciplinary research organization [J]. Higher Education Development Study, 2014( 2) : 25-29.

[4] Dai Zhihua, Xia Lu. Application of regional collaborative inno-vation mode in scientific research management in colleges[J].Journal of Shanghai Jiaotong University, 2013 ( 10 ) : 1649 $-1652$.

[5] He Yubing. The oretical model of collaborative innovation of industry university research[J]. Science Research, 2012(7) : 7-10. 